\title{
Research on the Current Situation of Industrial Structure and Upgrading Path in Hubei Province under the Background of Central Rise
}

\author{
Kang Li \\ Business School, HuBei University.
}

\begin{abstract}
The development of the industrial structure affects the development of the regional economy. From the implementation of the rise of central China to the present, while the industrial structure of Hubei Province is developing, there are also ity. unreasonable phenomena. This article analyzes the industrial structure of Hubei Province from 2004 to 2018.It first analyzes the current situation of the industrial structure of Hubei Province, the current situation of the industrial structure, the existing problems and reasons, and finally proposes the path of industrial structure optimization in Hubei Province based on the analysis results.
\end{abstract}

Keywords: Industrial structure; Central rise strategy; Optimization path
*Correspondence to Author:

Kang Li

Business School, HuBei Univers-

How to cite this article:

Kang Li. Research on the Current Situation of Industrial Structure and Upgrading Path in Hubei Province under the Background of Central Rise. Global journal of Economics and Business Administration, 2020, $4: 26$

\section{eScî̀Pub}

eSciPub LLC, Houston, TX USA.

Website: http://escipub.com/ 


\section{Introduction}

During the "two sessions" held in March 2004, Premier Wen Jiabao explicitly put forward the idea of "promoting the rise of the central region" for the first time in the government work report, which caused great concern among people in central provinces. In December 2004, at the Central Economic Work Conference, "Rise of Central China" was included in the six tasks of economic work in 2005. This is the first time that the country has put "the rise of the central region" on the agenda, and it is another measure of the central government to carry out macro-control on the "central collapse" after the "five overall arrangements." The central government's macro-control over the "central collapse" phenomenon expresses the central government's determination to try to resolve this focus issue as soon as possible. Prior to the Central Economic Work Conference, the central regions generally referred to the five provinces of Hubei, Hunan, Henan, Anhui, and Jiangxi. The five provincial government departments, academia, and industry are very concerned about the rise of the central region, and organized relevant departments to conduct extensive research, demonstration and countermeasure research.

Hubei Province, as a "nine provinces' thoroughfare", is a transportation hub in the hinterland of our country. Hubei must focus on building an important strategic fulcrum for the rise of the central region. This is the scientific positioning of the CPC Central Committee on the development of Hubei from the level of national strategy. It is also an important goal of economic and social development determined by the Ninth Party Congress of Hubei Province. In 2018, Hubei's economy has made steady progress and its industrial structure has been steadily upgraded. Hubei Province achieved a GDP of 3.936655 trillion yuan, an increase of $7.8 \%$ at comparable prices, 1.2 percentage points higher than the country, and 0.3 percentage points higher than the expected development target. It restrained the trend of unilateral decline for 7 consecutive years. The added value of the first industry was 354.751 billion yuan, an increase of $2.9 \%$; the added value of the second industry was 1.708895 trillion yuan, an increase of $6.8 \%$; the added value of the tertiary industry was 187.3009 billion yuan, an increase of $9.9 \%$, and the proportion of the three industries was $9.0: 43.4: 47.6$. With the rapid economic development of Hubei Province, the industrial clusters of Hubei Province have also expanded. Private enterprises are the leading development model for the development of industrial clusters in Hubei Province. However, due to the unbalanced industrial structure in Hubei, the ability of industrial clusters to absorb industrial clusters is insufficient, and the expansion of industrial clusters is slow. At present, Hubei's primary industry has a large base and low efficiency, and the employment share is still close to half. Factors such as low industrial proportion, imbalance of light and heavy structure, and slow growth of the private economy have led to a continued decline in the share of employment in the secondary industry. At the same time, the lack of strong support from agriculture and industry, Hubei's tertiary industry in recent years has also declined employment capacity. The unbalanced industrial structure has greatly affected the economic development of Hubei Province.

The division of industrial structure, the relationship between various industries, and the leading industries will all affect the pattern and speed of economic growth in a country. A rea- 
sonable industrial structure is a necessary condition for economic growth. An important driving factor for sustained and stable economic growth is the increase in productivity, which can be explained by the optimization of resource allocation, the improvement of resource quality, and technological progress. Through the adjustment of the industrial structure, resources (such as technical resources, human resources, etc.) are re-allocated and higher utilization efficiency is obtained. In this way, resources can release more energy, and the quality of resources will be further improved, thereby increasing productivity and accelerating economic growth. Conversely, if resources cannot be reasonably allocated through industrial restructuring, economic growth will be hindered. For example, during the period of economic and social development, the labor force is mainly concentrated in the agricultural sector, a weak industry with relatively slow progress in labor productivity. Will decrease. If the labor force is released from traditional agriculture and relocated to the industrial sector through the adjustment of the industrial structure, the development of modern industry will lead to an increase in labor productivity, and economic growth will accelerate.

At the same time, industrial structure affects technological progress and development. The adjustment and upgrading of the industrial structure can promote technological progress, and once a country or a region's leading industry technology is improved, it will promote a large leap-forward development of the economy or society of that country or region. According to the imbalanced development strategy and the "development pole" theory, leading sectors and industries with innovative capabilities can be used as a driving force to promote the development of other industries, thereby stimulating economic growth to accelerate. If in a certain period of time, in a country's industrial structure, the leading sector has high productivity and innovation capacity, can carry out continuous technological, technological and product innovation, and can spread these innovations to other industries, attracting and Concentrating large amounts of capital and expanding production The scale has a huge economy of scale effect, which can not only reduce social production costs, but also expand demand for products in other sectors, thereby driving the entire national economy to increase rapidly. However, industrial upgrading and structural adjustment are an uninterrupted process and a long and painful process. When this process stagnates and slows down, it will stifle economic development and social progress.

\section{Analysis of the Status of Industrial Stru- cture in Hubei Province}

Since China's market-oriented constitutional reform in 1978, Hubei's economy has achieved rapid development, and its industrial structure has been continuously optimized, which has promoted the rapid growth of the national economy. In general, the following points appear.

\subsection{Three industrial structures have gradu- ally improved}

Changes in the industrial structure not only reflect the process of economic development, but also reflect the results of economic development. In recent years, with the acceleration of the industrialization and urbanization process, the industry in Hubei Province has gradually decreased the proportion of the primary industry, and the proportion of the secondary and tertiary industries has steadily increased. The level of the industrial structure has been further improved. In 2018, Hubei's industrial structure 
ratio was 16.5 to 42.8 to 40.7 , showing a "two, three, one" structure. The three industries are in the same order as the country, but compared with the national average in 2011 , the primary industry is still 3.9 percentage points higher, the second The industry was 4.7 percentage points lower and the tertiary industry was 0.8 percentage points higher. Among the three major industries, the proportion of the secondary industry has steadily increased, and the industry-led industrial structure has been formed and further strengthened.

1.2 Industry is the main body of the secondary industry, and manufacturing is the main body of industry

\subsubsection{Traditional industries still account for a large proportion}

The traditional industries of Hubei Province have formed an industry structure with eight major industries as the main body. The top eight industries with a larger total are automotive, electric power, steel, textile, electronics, chemical raw materials and chemical manufacturing, tobacco and agricultural and sideline processing . In 2018, the eight major industries realized industrial added value of 138.497 billion yuan, accounting for $69.0 \%$ of the province's industry.

\subsubsection{High-growth industries are gradually formed}

In recent years, Hubei has formed a number of well-growth industries, which have significantly enhanced comparative advantages, and formed a linkage with the upgrading of the consumption structure, and a number of high-growth industries have gradually formed. From 2008 to 2018 , the sales revenue of the power, food, tobacco, textile, electronics, and pharmaceutical industries increased by 2.6 times, $84.5 \%$, $72.7 \%, 47.7 \%, 75.6 \%$, and $22.4 \%$; steel, non- ferrous metallurgy, building materials, metal products, etc Industries increased by 1.4 times, 1.5 times, $36.8 \%$, and $32.9 \%$; general equipment, transportation equipment, electrical machinery, chemical raw materials, and petroleum processing industries increased by 1.4 times, $57.7 \%, 77.3 \%, 1$ times, and 1.2 times, respectively.

\subsubsection{The pilot effect of strategic industries} is beginning to appear, and the industrial structure has been effectively improved

From the perspective of Hubei's industrial development, at present, strategic industries such as high-tech industries such as optoelectronic information, lasers, bioengineering, new medicine, and new materials, with modern equipment industry and opto-mechanical integration as the leader, have been initially formed. In 2018, six major industries including the general equipment manufacturing industry, special equipment manufacturing industry, transportation equipment manufacturing industry, electrical machinery and equipment manufacturing industry, communication equipment computer and other electronic equipment manufacturing industry, instrumentation and cultural office machinery manufacturing industry in our province The total industrial added value and the number of employees account for $27.3 \%$ and $24.5 \%$ of the province's industry, respectively. In 2018 , the value-added of the high-tech industry in the province was 83.392 billion yuan, an increase of $23.5 \%$, with significant economic benefits.

\subsection{Speed up the adjustment of the internal structure of the service industry}

In recent years, the proportion of Hubei service industry in the total economic volume has steadily increased, and the internal structure has undergone positive changes. The share of 
traditional industries has continued to decline, social undertakings have maintained steady growth, and the scale of modern service industries has been increasing year by year. In 2018 , Hubei's traditional service industry continued to develop and still dominated. In 2011, the added value of transportation, storage, post and telecommunications, and wholesale and retail trade catering industry accounted for $41.7 \%$ of the added value of the tertiary industry. The proportion of modern service industries is on the rise, and emerging industries such as information transmission, computer services and software, services, and real estate have developed rapidly. In 2018, the value-added of information transmission, computer services and software industry, service industry, and real estate industry accounted for $5.8 \%, 6.4 \%$, and $8.26 \%$ of the added value of the tertiary industry, which were 0.6 and 0.1 percentage points higher than the previous year. The added value of the modern knowledge industry, which consists of science and technology services, education, health, culture and entertainment, news publishing, radio and television, accounts for $20.7 \%$ of the tertiary industry.

The overall performance of the three major industries is that the primary industry has declined, the decline trend is obvious, and the decline rate is fast. The overall trend of the proportion of the secondary industry is rising steadily. The tertiary industry has developed relatively fast, but its proportion in the entire industrial structure is still small. At the same time, the interaction among the three industries in Hubei Province is poor, so it is necessary to make adjustments to the overall coordination among the industries in Hubei Province and their own coordination.

\section{Problems of Industrial Structure in Hubei}

\subsection{The development of primary industry and basic industry is lagging}

First of all, agriculture belongs to the primary industry sector of the national economy. The backwardness of agricultural development is not only the reason why other industrial sectors cannot develop quickly, but also the relatively backward performance of other industrial sectors. Although Hubei's primary industry accounts for a large proportion of the three major industries, it has a low level of technology, a single product, and a severely backward development level. Secondly, Hubei is far from the coast and developed areas. The infrastructure such as transportation and postal communications has always been backward, and to a large extent cannot meet the sustainable development of the regional economy. On the other hand, Hubei enterprises and the government do not pay attention to the development of basic industries and industries that are complementary to the leading industries. Instead, they are blindly investing in the development of general industries with narrow and short-term returns.

\subsection{Progress in the adjustment of the sec- ondary industry structure is slow, structural conflicts are prominent, and industrial qual-} ity is low

After the founding of the People's Republic of China, many central and western regions, as the rear of the national strategy, have largely become the energy and raw material supply bases that serve the eastern region in the regional division of labor. Many large and medium state-owned enterprises are mostly mining industries with relatively low value-added. And energy and raw material industries, and the depth of industrialization and processing levels are not high. Although the scale of our prov- 
ince 's industry has expanded rapidly in recent years, production capacity and output have also increased rapidly, but China 's level of per capita output is still low. Moreover, the technological equipment is relatively backward, the scientific and technological content is generally low, and the degree of correlation between industries is not high. It is difficult to exert the diffusion effect that the industry should have. Therefore, the low level of industrialization makes Hubei face a great challenge to rationalize the adjustment of industrial structure under the new economic situation.

2.3 The development scale of the tertiary industry is small and the level is low, showing structural defects.

The tertiary industry in Hubei Province has played the role of the main channel in employment, but the proportion of the added value of the tertiary industry to the GDP has always been unsatisfactory, and currently it is only a little over $40 \%$. The investment in the tertiary industry is small and the effect is rapid. In recent years, it has been encouraged and supported by governments at all levels, especially local governments. Institutional and policy obstacles have been gradually overcome, but the output value created by it has not grown fast enough, and the proportion of increase has not been large enough. How to accelerate the development of the tertiary industry in Hubei is an important issue for the optimization of industrial structure.

\section{Analysis of the causes of the problems in the industrial structure of Hubei}

3.1 Analysis of the reasons for the lag in the development of the primary industry

First of all, from the perspective of the internal structure of agriculture, the current proportion of planting is still too large, and the crop indus- try is dominated by food crops. Its industrial structure is a single-type industrial structure with planting as the mainstay. The proportion of forestry, animal husbandry and fishery is relatively small. The single characteristic of the agricultural industrial structure is very obvious. At the same time, the processing level of agricultural and sideline products and the level of agricultural marketization are significantly lower. Compared with the coastal provinces, the agricultural product industry in Hubei Province has a large gap. Each year, only a small number of agricultural products enter the market through processing, and many coastal provinces are as high as $70 \%$. This makes it difficult to convert the advantages of Hubei's agricultural provinces into economic provinces.

Secondly, in recent years, Hubei's agriculture and rural economy have developed rapidly, the output of major agricultural products such as grain has continued to increase, and agricultural infrastructure construction and production conditions have improved. However, on the whole, the foundation of agriculture is still weak, and its ability to resist natural disasters is not strong. Due to low per capita arable land and surplus labor force, the benefits of agricultural production are relatively low, and farmers' income has grown slowly. In addition, farmers' low cultural level and weak ability to master advanced science and technology also severely restricted the development of Hubei's primary industry. The lag of the primary industry economy is a fundamental structural contradiction in the current Hubei economy, which affects all aspects of economic life

\subsection{Reasons for the lag in the level of the secondary industry}

3.2.1 The proportion of state-owned enterprises in Hubei is large, and the flexibility of 


\section{the operating mechanism is poor}

After years of adjustments and asset reorganizations, large economic changes and capital structure of large and medium-sized industrial enterprises in Hubei Province have taken place. But overall, the pace of reform of large and medium-sized enterprises is significantly slower than that of small enterprises. Compared with the whole country and coastal provinces and cities, the overall scale of Hubei's state-owned industry accounts for a significantly higher proportion of industry. The flexibility of its operating mechanism is obviously not as good as that of non-state-owned enterprises and small enterprises, and large and medium-sized enterprises are less sensitive in responding to their own actual and market changes.

\subsubsection{Poor scale efficiency and unreasona-} ble resource allocation

In some industries that require high economies of scale, enterprises are small and scattered, and their economies of scale are poor. Taking the automobile manufacturing industry as an example, only the two companies in the industry, Dongqi and Shenlong, have an output value of more than 4 billion yuan, and the annual output of these two companies is still far behind the best in the domestic industry.

\subsubsection{Irrational industrial technology struc-} ture

First, due to insufficient long-term investment in technological transformation, some traditional industrial equipment is seriously aging, and the organic structure of technology is low; second, due to the lack of cost constraints and incentives for investment activities, objective separation of science and technology and industry, and low technology commercialization capabilities And other conditions. In developed countries, $70 \%$ to $80 \%$ of the increase in labor productivity and economic growth is achieved through science and technology, while Hubei's current scientific and technological progress contributes only about $30 \%$ to economic growth From the outside of the industry, some emerging technology industries lack strong related industry support.

\subsubsection{The proportion of total industrial out- put value is declining}

Hubei's industrial development is faster than the country, but the proportion of industrial production in the country is declining. The overall level of economic benefits is lower than that of the whole country, and its ranking in the country has continuously shifted backwards. In recent years, Hubei's industry has reversed the long-term low-level fluctuations or ups and downs. The province's industry has maintained a rapid growth of more than $10 \%$ for four consecutive years, and has set a record higher than the national average for four consecutive years. However, the ranking of Hubei's total industrial production in the country has shown a downward trend.

\subsection{Reasons for the lag in the development of the tertiary industry}

\subsubsection{The tertiary industry is small in scale and not fast enough}

The tertiary industry in our province is dominated by lower-level service industries such as catering, commerce and retail. In 2018, the wholesale and retail trade catering industry accounted for $27.6 \%$ of the gross output of the tertiary industry, ranking first. The scale of the tertiary industry enterprises is small, the technology content is not high, and the added value created is low. The information services, financial services, consulting industry, and modern logistics industry, which represent the development level of the tertiary industry, are still far 
from the eastern region, although they have developed.

\subsubsection{Unbalanced development in the ter-}

\section{tiary industry}

The logistics industry accounts for a large proportion in the traditional tertiary industry, and the emerging tertiary industry is underdeveloped. In the tertiary industry of Hubei Province, in addition to the logistics service industry, the industries that serve production and residents' life are developing very slowly and are far from meeting demand. As a result, the prices of these service industries cannot accurately reflect their value.

\subsubsection{Unreasonable internal labor force al- location in the tertiary industry}

A large number of low-quality labors have been deposited in the catering industry and the retail industry, while the number of employees in the industry that meets the needs of marketization and informatization is insufficient, restricting the further development and structural upgrade of the tertiary industry.

\section{Optimization of Industrial Structure in Hubei Province}

Aiming at the strong and weak factors of the industrial structure upgrade in Hubei Province, this article focuses on supply-side structural reforms Line, guided by the demand, especially the trend of consumption upgrade, and led by the scientific and technological innovation model, proposed the development of a six-in-one cooperative operation path.

\subsection{Demand-driven optimization path based on optimizing consumption structure}

Demand is one of the basic driving forces for upgrading and optimizing the economic structure. Due to the weak impact of consumer demand on the industrial structure in Hubei Province, domestic demand is not enough in the industrial perspective. Although Hubei Province has gradually got rid of the past industrial development model, the agricultural population still accounts for a large proportion. It is necessary to earnestly ensure the income of rural residents and increase farmers' consumption. If necessary, adjust agricultural product support prices to enhance the competitiveness of agricultural products markets. Followed by the industrial process of Hubei Province, The investment policy and loan policy are more biased towards the interests of enterprises and industrial manufacturing, and there is an urgent need to establish A reasonable social security system will make residents feel more at ease with consumption and further stimulate consumer demand. At the same time The development direction of the consumption structure adjusts the industrial structure, especially the development of the tertiary industry, targeting different consumption structures Provide multi-level consumption policies.

From a market perspective, the provincial market must strive to eliminate the situation of local market segregation and industry segregation, Demand has become an effective demand market that is driving industrial upgrading. On the other hand, we must also pay attention to the development of foreign markets. Strategy: First, seize the opportunity of the rise of central China and give full play to Hubei Province as a rising province. Central role and growth pole effect. The second is to take advantage of the Yangtze River Economic Belt to undertake industrial transfer, rely on the construction of the experimental zone, and give full play to the industry's international competitive advantages. Domestic and external demand form a joint force to promote industrial development and form a new situation in Hubei Province's inno- 
vative development.

\subsection{Supply-Promotion Path with Expanded Human Capital as a Booster}

Talent cultivation has played a key role in the period of industrial structure upgrade. Although Hubei Province has many high-level human capital advantages, the level of basic education has affected the progress of human capital. Education level On the one hand, it will hinder regional economic growth and thus restrict the optimization and upgrading of the industrial structure; on the other hand, This makes Hubei Province compete with other developed provinces and cities for industries that rely on labor progress and high-tech development. It is not obvious or even inferior, which limits the development space of the industrial structure. Therefore, human capital should be used as It is a booster for industrial upgrading and forms a diversified and multi-form talent development model. Human capital should be increased first In terms of investment, it is more effective to increase the number of years of education; secondly, attention should be paid to improving the quality of human capital. As China has a large population, there is no shortage of labor force, and the improvement of labor quality is the key. Hubei Province We should increase investment in re-education and encourage relearning to improve the quality of workers themselves. In terms of social supply, labor Force and capital complement each other, capital investment will promote the labor force to enter production and life better, and efficient labor Force will in turn promote the increase of capital, and the two will promote each other to make Hubei's industrial structure better.

\subsection{Innovation-driven path focusing on sci- entific and technological innovation and industrial innovation}

The Chinese economy has entered a new normal, and innovation drive has become the fundamental driving force for the upgrading and transformation of the industrial structure. Whether the relationship between the two can be coordinated is the key to effectively promote the upgrading of the industrial structure. With the promotion of innovative pilot provinces, the proportion of $R$ \& $D$ expenditures increased by $0.7 \%$. The growth of slightly new industries has greatly improved the industrial competitiveness of Hubei Province. It should be noted that the above research The research found that in Hubei Province, scientific research investment has played a restraining role in upgrading the industrial structure. The reason may be Anhui Province In terms of capital investment, research investment has increased year by year, but the proportion is still small. This is the transformation of science and technology to the industrial structure. The first limiting reason for type. For this reason, further increasing investment in research projects in Hubei Province is the first thing to do. From the perspective of the government, promoting the transformation of government functions from $R$ \& $D$ management to innovative services is to promote government departments. The first task of steadily improving the technology investment mechanism. From the perspective of the enterprise, it is necessary to highlight the status of corporate innovation To foster and develop a number of strategic emerging industries with large market potential and obvious comparative advantages, not restricted to domestic The industrial development environment and strengthening the level of opening up to the outside world will promote the overall level of the regional industrial structure. Province In terms of making full use of the "Wuhan City Circle" in 
economic development and industrial structure upgrade In terms of leadership, further deepen cooperation to promote industrial upgrading, increase investment in science and technology, encourage independent innovation, Promote the development of surrounding cities with its own advantages, and upgrade the industrial structure of Hubei Province into a leaping train track.

\subsection{Optimization of Industrial Structure with Foreign Trade as a Breakthrough}

As a developing province in central China, Hubei Province needs to make full use of the environment in which the level of openness is gradually deepening. The foreign capital will transform the relatively backward and relatively advantageous traditional industries in the province, starting from optimizing the internal structure of the industry. The current status of foreign investment in Hubei Province is that investment is mainly concentrated in the secondary and tertiary industries. And most areas around Wuhan. It can be seen that the problems of uneven distribution and imbalance of regional distribution of foreign capital in the industry are obvious. To promote foreign trade as a breakthrough to promote the upgrading of the industrial structure, we must first solve these problems. We can Industrial enterprises with export advantages provide government support, while exploring the potential of industrial enterprises to export, High production technology level, enhance the added value of products, and make foreign investment according to local conditions. As agriculture still exists Hubei Province, which has advantages, pays attention to the processing and export of agricultural products, absorbs advanced agricultural technology from abroad, and drives Hubei For agricultural development, the government en- courages exports through policy support. Giving play to the government's active role in policy Establish reasonable trade policies, reduce obstacles to export trade, and provide convenient conditions for export trade. Yangtze River Economic Belt Industrial transfer is not only an important opportunity but also a challenge for the transformation and upgrading of industrial structure in Hubei Province. The development of capital-intensive industries can mobilize enthusiasm in attracting investment in all aspects in the introduction of foreign capital, mitigate the insufficient development of Wuhan urban agglomerations, and stimulate the outward-looking vitality of enterprises; at the same time, the radiating role of Wuhan urban agglomerations can be leveraged Promote the common development of the province's economy and improve the overall industrial and economic development level of Hubei Province.

\subsection{Coordinated Development Path of In- dustry and City Supported by Accelerating New-type Urbanization}

New urbanization is an effective way to alleviate the current economic pressure and promote structural reform. First can add Great efforts will be made to promote land circulation and improve land utilization. In the process of migration, it provides convenience for rural migrants on issues such as housing and employment, and effectively promotes rural Surplus labor enters the city. Second, we should strengthen institutional supply in the process of promoting new-type urbanization. Factors such as the foundation of regional industrial development, resource endowment, and environmental carrying capacity play a fundamental role in institutional supply. Provide conditions for supply and demand balance. What's more important is that under the new normal, various regions will 
promote new urbanization Industry development supports urbanization, promotes the upgrading of industrial structure with urbanization, and grasps the role of industry and urbanization. Interaction mechanism to realize the integration of production and city and promote economic transformation and upgrading.

\subsection{Industrial policy promotion path sup- ported by differentiated policies}

By analyzing the evolution characteristics and trends of the industrial structure, it is found that the current industrial agglomeration effect in Hubei Province is not clear enough Obviously, only by promoting the appropriate concentration of industrial space can we fully improve the efficiency of resource space allocation. The flow of international factors, gaining a spatial dividend, and providing a long-term impetus for the comprehensive upgrading of industrial structure in Hubei Province, It also provides guarantee for sustained economic growth. Combined with the actual situation of the industrial structure of Hubei Province, City's industrial advantages, formulate long-term development strategies, optimize the industrial chain, and actively promote the formation of industrial agglomeration. With At the same time, we must also consider factors such as resource endowments, environmental bearing capacity, and location advantages in Hubei Province to adjust the industry. Space, strengthen the supporting role of urbanization, and build an interactive system of urbanization and industrial structure. Industrial knot in Hubei Province The structure of China still shows the level of "two three, one", and the development of the tertiary industry is relatively weak. The rapid development of the three industries is an important way to promote the optimization and upgrading of the industrial structure in Hubei Province. Hubei
Province There are differences between the level of industrial development and the level of economic development in prefectures and cities. Consider a variety of factors.

\section{References}

1. zhang liying. Research on optimization path of industrial structure in jilin province [D]. Yangzhou university, 2014.

2. tian maode, MAO yanghai. A brief analysis on the realization path of industrial structure optimization in Tibet [J]. Journal of hubei correspondence university (06):116-117.

3. sun ling, han runchun. Analysis of optimization path of tangshan industrial structure based on co-integration theory [J]. Journal of north China university of science and technology (social science edition), 2013, 13(1):24-27.

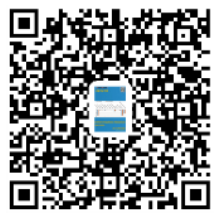

